\title{
An introduction to philosophical medical ethics: the Arthur case
}

\author{
RAANAN GILLON
}

In November 1981 a respected paediatrician, the late Dr Leonard Arthur, was acquitted of the attempted murder of a newborn infant with Down's syndrome for whom he had prescribed dihydrocodeine and "nursing care only" after the baby had been rejected by his mother. The complexity and difficulty of the case make it a suitable backdrop for this series of articles introducing philosophical medical ethics.

\section{What it's not}

Rather than starting with an account of what I mean by this term I would prefer to start by stating what philosophical medical ethics is not. It is not the enterprise of quoting or even of drawing up professional codes of conduct. It is not an account of the legal constraints on doctors' behaviour in medicomoral contexts. It is not a sociological/psychological/anthropological/historical effort to discover the attitudes, mores, or ethos of a particular community, medical or otherwise. Finally, it is not the expression of religious rules or sentiments.

This is in no way to denigrate any of these activities. In particular, it is not to denigrate what might be called traditional medical ethics - that is, the long and honourable tradition in which doctors have established and promulgated among themselves rules and codes of behaviour considered to be morally binding. As I hope to show, however, philosophical medical ethics is additional and complementary to these other activities and ultimately can be expected to reinforce the traditional activity known as medical ethics.

\section{What it is}

So what is philosophical medical ethics? Professor David Raphael gives a useful thumbnail account of philosophy as being "the critical evaluation of assumptions and arguments" and of moral philosophy as being philosophical inquiry about norms, values, right and wrong, good and bad, and what ought and ought not to be done. ${ }^{1}$ In similar vein, medical ethics (I use the terms ethics and moral philosophy interchangably) is the analytic activity in which the concepts, assumptions, beliefs, attitudes, reasons, and arguments underlying medicomoral decision making are examined critically.

Medicomoral decisions I take to be those that concern norms or values, good or bad, right or wrong, and what ought or ought not to be done in the context of medical practice. At one level the purpose of philosophical medical ethics is simply to make such decision making more thoughtful and intellectually rigorous. Its ultimate purpose, as I (admittedly contentiously) see it, is to construct and defend a comprehensive and coherent moral theory for medical practice based on universal principles applying to all and capable of justifying particular lines of conduct in individual cases. This holy grail has certainly not been reached and may well be essentially unattainable. Perhaps the best that may realistically be hoped for are several competing theories based on widely acceptable principles. Either way, the activity of philosophical medical ethics is fundamentally critical; it lies full square in the socratic tradition that considers "the unexamined life is no life for a human being."

\section{The Arthur case}

The first and crucial task of philosophical medical ethics (which I shall often call simply medical ethics) is to differentiate the issues. The Arthur case manifests a quite remarkable variety of medicomoral problems, and in the remainder of this first article I shall try to untangle these. In subsequent articles I shall analyse many of these issues separately, as well as some of the (surprisingly few) substantive issues in medical ethics that the Arthur case does not raise. First then, a brief outline of the moral "prosecution" and "defence" of 
the sort of treatment that Dr Arthur provided for the baby John Pearson. Although all the arguments I describe below were used either in the trial itself or in discussion of the trial, what follows is not intended, as I have indicated, to be a legal analysis but an effort to clarify the medicomoral issues raised.

\section{THE MORAL CASE FOR THE PROSECUTION}

The moral case for the prosecution runs something like this:

(1) All innocent human beings have a fundamental right to life; (corollary la) it is wrong to kill innocent human beings; (corollary $\mathrm{lb}$ ) it is wrong to deny innocent human beings reasonably straightforward protection against life threatening conditions. Furthermore, (2) doctors in relation to their patients, and parents in relation to their children, have greater than normal duties to protect the human beings in their charge. (3) It would obviously be wrong to give a normal infant, even if rejected by his or her parents, nursing care only, which is (4) only morally permissible in some cases where patients are already dying. Similarly, (5) it would be wrong for a normal but rejected infant to be given a potentially dangerous pain killing drug when its pain or distress could be alleviated by feeding, comforting, and, in the case of chest infection, probably by treatment with physiotherapy and appropriate antibiotics. (Illustration: imagine giving dihydrocodeine and nursing care alone to a normal but rejected infant distressed by three month colic, simple hunger, or a chest infection.)

(6) It would also clearly be wrong for an older handicapped and rejected child, even one with Down's syndrome, reversibly unconscious after, say, a road accident to be given nursing care alone or to be treated with potentially dangerous pain killers alone. Furthermore, (7) distinctions between acts and omissions, between killing and letting die, could clearly not possibly justify such life threatening treatment of normal rejected infants or of older rejected and handicapped children. (8) The newborn child with Down's syndrome is no less an innocent human being than are the normal newborn infant and the older handicapped child.

(9) As it is wrong to treat the older handicapped child with nursing care only and dihydrocodeine it logically follows that it is wrong to treat the newborn infant with Down's syndrome in this way, even if parental rejection has regrettably occurred. Furthermore, (10) under the law like should be treated as like; (11) as such treatment of normal infants or of older handicapped infants would properly be punished under the law so (12) it ought to be punished when meted out to rejected newborn infants with Down's syndrome.

That in summary is the moral argument of the Life organisation, whose members instigated the prosecution of Dr Arthur, and it would probably be the position of the Roman Catholic church and other orthodox religions, as well as of many other opponents of what Dr Arthur did.

\section{THE MORAL CASE FOR THE DEFENCE}

As for the defence, a composite summary culled from the trial and comment about the case runs something like this: (13) In general, a doctor's duty is to do all he reasonably can to preserve the lives and (14) restore or preserve the health of his patients. (15) He also has a duty to relieve, prevent, or minimise their pain and suffering. (16) In rare cases infants are born with such severe physical and or mental handicaps that medical intervention to increase the baby's chances of survival is not clearly justified. (17) Such lives, if they are preserved, are likely to be handicapped to a considerable and sometimes very severe degree and their chances of ordinary human flourishing are low. (18) Moreover, they are likely to impose a great burden of care on their parents (or other guardians) or (19) on the community if their parents reject them or die; also (20) other members of the family may be adversely and severely affected by this burden.

On the other hand, (21) some parents find the responsibility of this additional burden enriching for themselves and the rest of the family, and (22) some handicapped infants grow up to have very worthwhile lives. (23) In such variable circumstances the parents are the proper people to decide whether life preserving medical care should be given to the severely handicapped infant after (24) being given information by the doctor about the possible outcomes and? their likelihood so far as these can reasonably be assessed. (25) It is arrogant and potentially cruel for doctors or anyone else to impose 2 . decision contrary to the parents' own wishes in such circumstances, provided (26) there is no reason to suspect that the parents ared incompetent to decide or (27) are acting maliciously. (28) Whatever their decision, the parents should be supported in its implementa? tion and their suffering minimised. (29) If the decision not to: employ life preserving medical treatment is taken the infant's suffering should also be minimised, and (30) pain killers ande sedatives can properly be used for this purpose (31) even if they also. increase the chances that the infant will die, for instance, by depressing respiration or appetite.

(32) A doctor must not kill his patient but (33) he is not obliged ing all circumstances to prevent his patient dying. In particular, (34) he may in good conscience let severely handicapped very young infants ${ }^{\circ}$ die when their parents do not wish for life saving medica $\vec{F}$ intervention. (35) Such cases are usually very distressing for aln concerned, but (36) least distress arises if the decision making is lefe to parents in consultation with experienced doctors, all acting ir good faith and mutual trust. (37) The addition of legal procedureso and (38) the presence of potential spies from pressure groups can; only serve to increase the parents' already considerable anguish and possibly also to increase the likelihood of the doctor practising "defensive medicine" rather than doing what he believes to be best.

\section{THE ISSUES RAISED}

I suspect that these two accounts of the rights and wrongs of theArthur case incorporate between them the views of the greato majority of practising doctors. They also incorporate a wide variety of substantive issues in philosophical medical ethics. Thus the prosecution's premise that all innocent human beings have a right tos life (1), by making a rights claim (What are rights? Why should weo accept that there are rights? Are there different sorts of rights? Wha\% follows ?), immediately elicits the fact that there are two major types of ethical theory. One type is based on rights and duties (so called deontological theories of ethics, from the Greek word for duty; much religious moral theory is deontological) and the other on the effects or consequences of actions (consequentialist theories of ethics, of which utilitarianism in its various forms is the main example).

Premises 1 to 6 in the prosecution's case all depend in some measure on acceptance of a deontological theory of ethics, as do3 premises 13,14, and 15 in the defence. On the other hand, premisesio 17 to 22 all depend on consequentialist assumptions in that the happiness, distress, or flourishing (quality of life) resulting from an action are assumed to determine its rightness or wrongness. Both? types of theory have major attractions and flaws.

The premise that it is wrong to kill innocent human beings (la) raises the interesting issue of innocence and the crucial issue of what do we mean by human being in the context of moral reasoning. Don we mean any human being, from conception to cardiorespiratory death? any sentient (conscious) human being? any human being showing brain activity? Is there a morally important distinction to be made between a living human being and a living human person that might help us here? Clearly la is relevant to some of the mose? fundamental and familiar problems of medical ethics including those of abortion, euthanasia, and brain death.

Premise $1 \mathrm{~b}$, and more specifically premise 7 , raise the philosophi-胥 cal problem of acts and omissions. Many, perhaps most, doctorso rely heavily on the moral importance of this distinction in the context of killing versus letting die and it underpins premises 16, 23, $29,32,33$, and 34 . The profound question, however, remains: can a moral decision ever properly turn solely on the question of whether a person's behaviour is to be classified as an act or as an omission?oㅡㄹ This issue will be discussed in the context of two other doctrines of 
Roman Catholic moral theology often employed in medical ethics, notably the doctrine of ordinary and extraordinary means (perhaps hinted at in premise 16) and the doctrine of double effect ( 30 and 31).

Premise 2 evokes the issue of the relationship between people's general moral obligations and those imposed by their roles. For example, can it ever be right for a person to do something as a doctor that he would consider to be morally wrong in his role as an ordinary person? (What about a Roman Catholic doctor who refuses to arrange to perform an abortion but refers the patient, as is now professionally expected, to a doctor who has no moral objections?)

The whole argument (1-9) illustrates a basic method of moral argument. This is, to find a case or cases that are undisputed and argue that the case in doubt is morally similar to these and therefore should be treated similarly. Premise 10 alludes to the enormous philosophical problem of justice and 11 to that of punishment.

The case for the defence of Dr Arthur raises additional medicomoral issues. Thus premises 13,14 , and 15 imply that the moral foundation of medicine consists of certain duties; but in what circumstances do these duties apply? Again, what do we mean by "life" in this context, and by "health"? What sorts of suffering is it a doctor's duty to minimise? - all sorts? - and what is the relative importance of these duties, and how are doctors to choose between them when they conflict? Premises 17 and 22 provoke the question: what part, if any, should assessments of quality of life play in medicomoral decision making? Premises 18 to 21 raise the issue of how much the effects of medical treatment on people other than the patient should be taken into account: what, for example, is the role of the family and what is the role of cost benefit analysis in medical ethics?

Premises 23, 24, and 25 are highly contentious claims: should patients or their families, or both, make difficult and often anguishing medicomoral decisions that concern them or is this properly the responsibility of the doctor? Here the issue of personal autonomy is crucial; do people have the right (perhaps even the duty) to make their own moral decisions regardless of how difficult or distressing these might be, or should a doctor's duty to reduce his patients' suffering extend to diminishing their autonomy by taking such decisions for them? Associated with this issue of autonomy is that of lying to, deceiving, or incompletely informing patients in order to save them suffering.

Premise 34 raises the issue of conscience and 36 that of good faith, but what are these and what are their proper roles in (medical) ethics? The important question of the relation between law and morals arises in connection with premise 37 , and 38 concerns the issue of what the Americans call "whistle-blowing": when if at all should someone who believes that an action approved and taken by fellow workers is in fact a heinous crime (murder for instance) "blow the whistle?"

\section{Conclusion}

The Arthur case thus provides a substantial basis for an introduction to philosophical medical ethics, and I shall pick up many of the issues raised in subsequent articles.

It is vital to remember that the purpose of this series is not to promulgate a particular moral theory. It is simply to encourage more rigorous analysis than is customary of the moral dilemmas that confront all practising doctors.

We each must choose our medicomoral framework but, as with all other aspects of medical practice, we have a responsibility to choose critically, eschewing prejudice and rejecting slipshod, lazy, or incoherent reasoning. In this context the study of philosophical medical ethics can, I believe, be of some help.

\section{References}

1 Raphael DD. Moral philosophy. Oxford: Oxford University Press, 1981:1,8

2 Plato. Apology. In: Jowett B, translator. The dialogues of Plato. Vol 1. London: Sphere Books, 1970:80.
In a small works making fibre glass canoes one of the processes requires the application of a gel coat coloured with cadmium based pigments with a spray gun. Although the sprayer is provided with a mask other workers in the vicinity are not and there is no local exhaust ventilation. Does this process constitute a hazard from the cadmium pigments and is it acceptable apart from the pigment aspect?

Most glass reinforced plastic boats are manufactured from polyester or epoxy resins, which may be coloured with cadmium based pigments. These contain inorganic salts such as cadmium sulphide (yellow) and sulphoselenide (red). Acute cadmium poisoning (presenting as chemical pneumonitis and, occasionally, pulmonary oedema) may follow the inhalation of fume or dust of any cadmium containing compound. In practice it is usually caused by cadmium oxide fume evolved during welding, soldering, or burning cadmium based alloys or coatings. Chronic poisoning attributable to cadmium pigments has not been reported. Nevertheless, all cadmium compounds are included in the current limits for occupational exposure. Other hazards associated with the manufacture of glass reinforced plastic products include dermatitis from contact with fibre glass and solvents, eczema or asthma in employees sensitised to resins, and exposure to styrene vapours liberated from glass reinforced plastic resin systems. ${ }^{2}-$ W R LEE, professor of occupational health, Manchester.

1 Health and Safety Executive. Occupational exposure limits 1984. London: HMSO, 1984. (Guidance note $\mathrm{EH} 40$.)

2 Health and Safety Executive. Toxicity Review 1. Styrene. London: HMSO, 1981

A woman in her late 40 s with two children is suffering from heavy menstrual bleeding well controlled by norethisterone ( $15 \mathrm{mg}$ daily). She does not want to have a hysterectomy but is it wise to continue with the norethisterone?

Norethisterone is a C-19 nor-steroid and as such possesses androgenic as well as progestogenic activity. In addition to causing obvious androgenic side effects such as acne, norethisterone also adversely affects carbohydrate and lipid metabolism. Plasma insulin concentrations are increased, reflecting impaired glucose tolerance ${ }^{1}$; and the plasma concentration of cholesterol in the high density lipoprotein fraction (HDL) is reduced, whereas that in the low density fraction (LDL) is increased. ${ }^{2}$ Thus the HDL/LDL ratio is lowered. These lipid effects are potentially serious because the incidence of cardiovascular disease is inversely related to the HDL-cholesterol concentration and directly related to a low $\mathrm{HDL} / \mathrm{LDL}$ ratio. ${ }^{34}$ These metabolic effects may explain the increased incidence of hypertension and arterial thromboembolic disease which have been associated with norethisterone in a dose dependent manner during oral contraceptive therapy. ${ }^{5}$

A putative increase in risk of cardiovascular complications during norethisterone administration is probably related to the presence of relevan antecedent factors, the duration of treatment, and also the dose. Short term treatment of a couple of months is unlikely to increase the risk significantly, but the same may not be true for long term treatment-especially in patients who are hypertensive, obese, or heavy smokers. If no suitable alternative long term treatment is either available or acceptable to the patient it would be sensible to try to minimise the metabolic effects either by reducing the dose or by prescribing a progestogen almost devoid of androgenic activity Norethisterone $0.7 \mathrm{mg}$ daily (two Micronor or Noriday tablets) and hydrogesterone (Duphaston) $20 \mathrm{mg}$ daily both achieve excellent secretory transformation within the endometrium (our unpublished observations) and are probably as beneficial as norethisterone $15 \mathrm{mg}$ daily in controlling anovulatory heavy menstrual bleeding.-M WHITEHEAD, senior lecturer consultant gynaecologist, London.

1 Spellacy WN, Buhi WC, Burk SA. Effects of norethindrone on carbohydrate and lipid metabolism Obstet Gynaecol 1975;46:560-3.

2 Farish E, Fletcher CD, Hart DM, Kitchener H, Sharpe GL. A long-term study of the effects of norethisterone on lipoprotein metabolism in menopausal women. Clin Chim Acta 1983;132 193-8

3 Gordon T, Castelli WP, Hiortland MC, et al. High density lipoprotein as a protective factor against coronary heart disease. Am f Med 1977;62:707-14

4 Yaari S, Goldbourt U, Evan Zohar S, Neufeld HN. Associations of serum high density lipoprotein and total cholesterol with cardio-vascular and cancer mortality in a seven year prospective study of 10000 men. Lancet $1981 ; \mathrm{i}: 1011-5$.

5 Royal College of General Practitioners. Oral contraception study: effect on hypertension and benign breast disease of the progestogen component in combined oral contraceptives. Lancet 1977;i:624. 